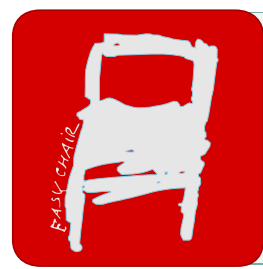

EPiC Series in Health Sciences

CAOS 2017. 17th Annual Meeting of the International Society for Computer Assisted Orthopaedic Surgery

\title{
Margin quality with Patient Specific Instruments (PSI) for bone tumor resection
}

\author{
Laurent Paul $\mathrm{PhD}^{1^{*}}$, Thomas Schubert MD $\mathrm{PhD}^{2}$, Robin Evrard ${ }^{2}$ and \\ Pierre-Louis Docquier MD $\mathrm{PhD}^{2}$ \\ 1*3D-Side, 1348 Louvain-La-Neuve, Belgium, 1p@ 3dside.eu \\ ${ }^{2}$ Cliniques Universitaires St-Luc, 1200 Bruxelles, Belgium
}

\section{Introduction}

Bone tumor resection and subsequent reconstruction remains challenging for the surgeon. Obtaining adequate margins is mandatory to decrease the risk of local recurrence. Improving surgical margins quality without excessive resection, reducing surgical time and increasing the quality of the reconstruction are the main goals of today's research in bone tumor surgical management. With the outstanding improvements in imaging and computerized planning, it is now a standard. However, surgical accuracy is essential in orthopaedic oncologic surgery (Grimmer 2005).

Patient specific instruments (PSI) may greatly improve the surgeon's ability to achieve the targeted resection. Thanks to its physical support, PSI can physically guide the blade yielding to a better control over the cutting process (Wong, 2014). Surgical time might significantly be reduced as well when compared to conventional method or navigated procedure. Finally, reconstruction may gain in rapidity and quality especially when allograft is the preferred solution as PSI can be designed as well for allograft cutting (Bellanova, 2013).

Since 2011, PSI have systematically been used in our institution for bone tumor resection and when applicable allograft reconstruction. This paper reports the mid- to long-term medical outcomes on a large series. 


\section{Materials and Methods}

Between 2011 and 2016, we systematically used PSI to remove bone tumors in 30 patients. The pre-operative planning involved the tumor delineation drawn on MRI by the surgeon. The MRI and obtained tumor volume were transferred to the CT-scan by image fusion (co-registration). Cutting planes were positioned around the tumor including a safe margin. The PSI were designed to ensure a sufficient stability but kept thin enough to limit the bone exposure. The PSI was manufactured by 3D-printing in a biocompatible and sterilizable material. PSI has been intraoperatively to cut the bone with predetermined margins.

Medical files were reviewed for large data collection: type, size and site of the tumor, pre-and post-operative metastatic status, bone and soft tissues resection margins, local recurrence, use of an allograft and a PSI for graft adjustment or not for the reconstruction, the fusion of the allograft when applicable, the follow-up time and early/late complications.

\section{Results}

Table 1 summarizes the results. Over a period of 5 years, 30 patients were operated on with PSI (10 osteosarcomas, 4 chondrosarcomas, 10 Ewing sarcomas and 6 other types of bone tumors). Mean follow-up was $27 \pm 20$ months. 18 cases out of 30 have more than 2 years follow-up and 13 out of 30 have more than 3 years of follow-up. Mean operating time was $6 \mathrm{~h} 02 \pm 3 \mathrm{~h} 44$. Mean size of the tumors was $8.4 \pm 4.7 \mathrm{~cm}$ and location was the upper limb in 5 cases, inferior limb in 15 cases and the pelvis in 10 occurrences. Metastatic disease developed postoperatively in 5 patients. Surgical margins in the bone were R0 in all cases but one case where a R1 surgery was planned to preserve a nerve root. We did not observe any local recurrence in the bone. Within soft tissues, margins were classified as R0 in 28 patients and R1 in 2 patients. In 26 cases, an allograft was used to reconstruct the bone defect. In 23 of those patients, the allograft was selected by CT scan and cut using a PSI. In the 3 allografts cut free-handily, only one demonstrated a fusion. Of the 23 cut with a guide, 12 fused completely, 2 demonstrated a partial fusion and 9 were not fused at the last follow-up. At the last follow-up, 2 patients were dead of disease, 5 were alive with metastatic disease and 23 were alive without disease. 


\begin{tabular}{|c|c|c|c|c|c|c|c|}
\hline & $\begin{array}{c}\text { mean } \\
\text { Size } \\
(\mathrm{cm})\end{array}$ & R0 & $\mathrm{R} 1$ & $\mathrm{R} 2$ & $\begin{array}{l}\text { mean age } \\
\text { (years) }\end{array}$ & $\begin{array}{c}\text { mean operating } \\
\text { time (hours) }\end{array}$ & $\begin{array}{l}\text { TOTAL } \\
\text { (nb) }\end{array}$ \\
\hline \multicolumn{8}{|l|}{ DIAGNOSIS } \\
\hline osteosarcoma & $8.2 \pm 3.6$ & 10 & 0 & 0 & $17.2 \pm 9.4$ & $4 \mathrm{~h} 41 \pm 1 \mathrm{~h} 11$ & 10 \\
\hline chondrosarcoma & $\begin{array}{r}10.6 \pm \\
6.5\end{array}$ & 4 & 0 & 0 & $56.1 \pm 8.3$ & $8 \mathrm{~h} 53 \pm 5 \mathrm{~h} 01$ & 4 \\
\hline ewing sarcoma & $\begin{array}{r}10.0 \pm \\
4.6\end{array}$ & 10 & 0 & 0 & $12.4 \pm 4.3$ & $5 \mathrm{~h} 24 \pm 2 \mathrm{~h} 21$ & 10 \\
\hline others & $5.0 \pm 4.1$ & 5 & 1 & 0 & $39.5 \pm 21.9$ & $7 \mathrm{~h} 25 \pm 6 \mathrm{~h} 09$ & 6 \\
\hline \multicolumn{8}{|l|}{ LOCATION } \\
\hline inferior limb & $6.4 \pm 3.8$ & & & & & $3 \mathrm{~h} 53 \pm 1 \mathrm{~h} 25$ & 15 \\
\hline superior limb & $9.3 \pm 5.6$ & & & & & $3 \mathrm{~h} 25 \pm 1 \mathrm{~h} 17$ & 5 \\
\hline pelvis & $\begin{array}{r}10.9 \pm \\
4.3\end{array}$ & & & & & $10 \mathrm{~h} 34 \pm 2 \mathrm{~h} 35$ & 10 \\
\hline TOTAL & $8.4 \pm 4.6$ & 29 & $1 *$ & 0 & $25.3 \pm 19.4$ & $6 \mathrm{~h} 02 \pm 3 \mathrm{~h} 44$ & 30 \\
\hline
\end{tabular}

Table 1: Summary of results

\section{Discussion}

Oncology is probably the field where PSI can bring the largest advantage when compared to the conventional procedure. Several papers have reported the use of PSI for bone tumor resection. All of them have shown very promising results on in-vitro experiments (Cartiaux 2014), cadaver experiment (Wong 2012) or small clinical series (Bellanova 2013, Gouin, 2014). None of these papers report a large patient series associated with a clinically relevant follow-up. This series is the first mid- to long-term follow-up series involving PSI tumor surgery. These results are showing strong evidences of clinical improvements. It comes into contradiction with PSI for total knee arthroplasty where controversial results on the patient's outcome has been reported (Thienpont 2014).

R0 margin has been systematically obtained for all bone cuttings, and local recurrence has been strongly decreased (3\%) when compared to the usual recurrence rates published in the literature (from $15 \%$ to $35 \%$ according to the location). 
Allograft fusion seems improved as well thanks to the shape-matching of the selected allograft and a close contact between host and allograft at bony junctions.

With a longer follow-up, these evidences should be stronger to definitely make PSI the best option for bone tumor resection.

\section{References}

Grimer R, Surgical options for children with osteosarcoma, The Lancet Oncology, 6(2),pp: 85-92, 2005.

Bellanova L, Paul L, Docquier PL, Surgical Guides (Patient-Specific Instruments) for Pediatric Tibial Bone Sarcoma Resection and Allograft Reconstruction, Sarcoma, 2013, 2013:787653.

Wong KC, Kumta S, Use of Computer Navigation in Orthopedic Oncology, Current Surgery Reports, 2(4), pp:47, 2014.

Gouin F, Paul L, Odri GA, Cartiaux O, Computer-Assisted Planning and Patient-Specific Instruments for Bone Tumor Resection within the Pelvis: A Series of 11 Patients. Sarcoma. 2014;2014:842709.

Cartiaux O, Paul L, Francq BG, Banse X, Docquier PL, Improved accuracy with 3D planning and patient-specific instruments during simulated pelvic bone tumor surgery, Ann Biomed Eng, 42(1), pp: 205-13, 2014.

Wong KC, Kumta SM, Sze KY, Wong CM, Use of a patient-specific $\mathrm{CAD} / \mathrm{CAM}$ surgical jig in extremity bone tumor resection and custom prosthetic reconstruction, Comput Aided Surg, 17(6), pp: 284-293, 2012.

Thienpont E, Schwab PE, Fennema P, A systematic review and meta-analysis of patient-specific instrumentation for improving alignment of the components in total knee replacement, The bone and Joint Journal, 96B(8), pp:1052-61, 2014. 


\section{Disclosures}

Laurent PAUL is co-founder of 3D-Side, company that designs, manufactures and commercializes patient-Specific Instruments for bone tumor surgery. 